\title{
Redes sociais e política educacional: análise do Instituto Ayrton Senna no twitter de 2013 a 2020
}

\author{
Social networks and education policy: analysis of Ayrton Senna Institute on \\ twitter from 2013 to 2020 \\ Redes sociales y política educativa: análisis del Instituto Ayrton Senna en \\ twitter de 2013 a 2020
}

\author{
RUI DA SILVA \\ https://orcid.org/0000-0003-3369-1285 \\ Universidade do Porto \\ Centro de Estudos Africanos \\ Porto, Portugal \\ THERESA ADRIÃOO \\ http://orcid.org/0000-0003-1181-5873 \\ Universidade Estadual de Campinas \\ Programa de Pós-graduação em Educação \\ Faculdade de Educação \\ Campinas, SP, Brasil
}

\begin{abstract}
Resumo: O artigo procura analisar a incidência do Instituto Ayrton Senna (IAS) expressa no Twitter observando as tendências identificadas nas mensagens, os usuários mencionados e as agendas veiculadas. Utilizando um corpus documental composto pelos tweets do Instituto Ayrton Senna de 2013 a 2020 realizou-se análise de conteúdo e análise automática de frequência de palavras dos tweets. Os resultados destacam que os tweets dão importância a questões inerentes ao conjunto Ciência, tecnologia, engenharia e matemática (STEM em inglês) e ao uso de evidências científicas, de pesquisas, citações ou de estudos para legitimar as posições defendidas pelo IAS. Também referências a organizações como UNESCO e OCDE são utilizadas para legitimar as ações e as opções tomadas pelo IAS.
\end{abstract}

Palavras-chave: Políticas educacionais; Instituto Ayrton Senna; Twitter; Redes sociais

Abstract: Este artículo pretende analizar la agenda del Instituto Ayrton Senna (LAS) expresada en Twitter observando las tendencias identificadas en los mensajes, los usuarios mencionados y las agendas transmitidas. A partir de un corpus documental formado por los tuits del Instituto Ayrton Senna desde 2013 basta 2020, se realizó un análisis de contenido y un análisis automático de frecuencia de palabras de los tuits. Los resultados destacan que los tuits dan importancia a cuestiones de la ciencia, la tecnologia, la ingeniería y las matemáticas y al uso de pruebas científicas, investigaciones o estudios para legitimar las posiciones defendidas por el LAS. La referencia a organizaciones como la UNESCO y la Organización para la Cooperación y el Desarrollo Económico (OCDE) se utiliza para legitimar las acciones y opciones adoptadas por el LAS.

Keywords: Politicas educativas; Instituto Ayrton Senna; Twitter; Redes sociales. 
Resumen: The paper seeks to analyse the agenda of the Ayrton Senna Institute (ASI) on Twitter by examining the trends identified in the messages, the users mentioned, and the agendas conveyed. Using a corpus of documents composed of the tweets of Ayrton Senna Institute from 2013 to 2020 we performed a content analysis and automatic word frequency analysis of the tweets. The results highlight that the tweets give importance to issues inherent to science, technology, engineering, and mathematics (STEM), the use of scientific evidence, research, citations, or studies to legitimise the positions defended by the ASI. Reference to organisations such as UNESCO and the Organisation for Economic Cooperation and Development is used to legitimise the actions and options taken by the ASI.

Palabras-clave: Education policies; Ayrton Senna Institute; Twitter; Social networks.

\section{INTRODUÇÃO}

O cotidiano de uma grande parte da população mundial é partilhado com ou por meio de tecnologias de informação e comunicação, estando estas interligadas com a nossa experiência cotidiana. Neste contexto, o Twitter é a plataforma líder de microblogging ${ }^{1}$ nas redes sociais ${ }^{2}$ (mensagens curtas até 280 caracteres) com o potencial de dar a conhecer visões e opiniões, de produzir narrativas (SAM, 2019; THELWALL; CUGELMAN, 2017; WELLER; BRUNS; BURGESS; MAHRT et al., 2014) e ainda de incidir sobre estas. Diferentemente de outras plataformas, cada tweet tem um comprimento limitado para comunicação aos usuários, de modo que a ferramenta exige a produção de mensagens mais diretas e simples (WELLER; BRUNS; BURGESS; MAHRT et al., 2014). O Twitter permite que os usuários escolham de quem receber as mensagens (ou seja a quem o usuário "seguirá"), procedimento que não requer reciprocidade. Permite ainda a comunicação interpessoal, e é utilizado como um local de debate em relação a notícias, política, negócios, pesquisas e entretenimento em tempo real (WELLER; BRUNS; BURGESS; MAHRT et al., 2014).

Para Blommaert (2020)

\footnotetext{
1 Mensagens curtas e concisas até 300 palavras que podem ter imagens, GIFs, hiperligações, infográficos, vídeos, e clips de áudio.

2 Em linhas gerais, entendida como a representação de "um conjunto de participantes autônomos, unindo ideias e recursos em torno de valores e interesses compartilhados”. (MARTELETO, 2001, p. 72)
} 
"Desde o início do século XXI, vivemos nossa vida social, cultural, política e econômica em um nexo online-offline, no qual ambas as "zonas" - a online e a offline - não podem mais ser separadas e devem ser vistas como fundidas em uma gama desconcertante de novas práticas online-offline de interação social, troca de conhecimentos, aprendizado, formação de comunidades e identidade. A chamada "revolução digital" já aconteceu, e segundo Florian Cramer (2014) tornou-se "histórica", entramos agora em uma era "pós-digital" na qual a inovação em grandes tecnologias é acompanhada por buscas de agenciamento pelas comunidades de base, pela criação de mídia pelas pessoas e sistemas híbridos de mídia.” (BLOMMAERT, 2020, p. 391-tradução livre)

As redes sociais, e em particular o Twitter, podem ser consideradas ferramentas privilegiadas nas negociações e na disseminação de temas relacionados às políticas educacionais adotadas por intervenientes ou agentes políticos nacionais e internacionais (SCHUSTER; JÖRGENS; KOLLECK, 2019). Nesta direção, compartilha-se da conclusão de Marteleto (2001, p.72):

"O estudo das redes coloca assim em evidência um dado da realidade social
contemporânea que ainda está sendo pouco explorado, ou seja, de que os
indivíduos, dotados de recursos e capacidades propositivas, organizam suas
ações nos próprios espaços políticos em função de socializações e mobilizações
suscitadas pelo próprio desenvolvimento das redes. Mesmo nascendo em uma
esfera informal de relações sociais, os efeitos das redes podem ser percebidos fora
de seu espaço, nas interações com o Estado, a sociedade ou outras instituições
representativas."

Tendo este aspecto em conta, o presente artigo procura analisar as tendências das publicações, os usuários mais frequentemente mencionados e as agendas ou pautas divulgadas pelo Instituto Ayrton Senna por meio do estudo das mensagens veiculadas em sua conta oficial no Twitter(@instayrtonsenna), durante o período de 2013 a 2020.

O Instituto Ayrton Senna (IAS) é uma organização não governamental sem fins lucrativos fundada no Brasil em 1994 após a morte do piloto brasileiro que lhe dá o nome. Associa-se à Ayrton Senna Foundation Limited, empresa ativa incorporada em 14 de dezembro de 1993 com a sede em Londres e gerida pela família do ex-piloto de Fórmula 1, cuja principal atuação refere-se à gestão da marca Senna. (ADRIÃO e PERONI, 2011).

Durante o período em que se mapeou os conteúdos do Twitter, a composição da equipe de Governança e Gestão do IAS sofreu importantes alterações: incorporou na sua estrutura Mozart Neves Ramos - ex coordenador geral da rede empresarial de advocacy Todos pela Educação (2007-2010) e membro do Conselho Nacional de Educação (desde 2007) - e o doutor em economia pela Universidade de Chicago, Ricardo Paes de Barros - ex. subsecretário da Secretaria 
de Assuntos Estratégicos da Presidência da República. No mesmo período, mais precisamente em 2015, o IAS criou o projeto EduLAb21, iniciativa com o objetivo de mapear e produzir conhecimentos e materiais sobre o que designam competências demandadas para o século XXI (VINCENT-LANCRIN, 2015) para redes públicas de ensino. A inicitiva patrocina a Cátedra Instituto Ayrton Senna no INSPER ${ }^{3}$, ocupada pelo mesmo Paes de Barros com o objetivo de fomentar o desenvolvimento de estudos e pesquisas na área de educação, e associase à Universidade de Ghent/ Bégica por meio de uma Cátedra coordenada pelo psicólogo Filip De Fruyt.

Segundo ADRIÃO (2018), no mesmo período, o IAS passou a integrar a NetFWD (Net Forward) da OCDE (Organização para a Cooperação e Desenvolvimento Econômico), rede global de fundações dedicadas a promover e otimizar o impacto da filantropia. A rede é constituída por um pequeno grupo de fundações que integram duas frentes de trabalho: uma relacionada à filantropia empresarial e a outra a inovações apoiadas por tais filantropos. As iniciativas correspondem a ações da Venture Philanthropy, expressão adotada pela OCDE, ou dos filantrocapitalistas como preferem Green e Bishop (2008) para se referir ao segmento constituído por organizações associadas a corporações e por milionários cujas doações funcionam como investimento empresarial: socialmente orientado, mas com retorno esperado. (ADRIÃO, 2018)

A essa perspectiva alinham-se os recursos que financiam as iniciativas do IAS, as quais derivam de Marketing Relacionado à Causa (MRC) - iniciativas de empresas que destinam parte de seu lucro ao IAS; Programa de Membership e Major Donnors - doação de pessoas físicas; Licenciamento das marcas Ayrton Senna e Senninha; Doação em folha de pagamento de trabalhadores de empresas "parceiras" e de fundos oriundos do Investimento Social Privado - doação voluntária de recursos privados para projetos de interesse público. Nesse sentido, amplia suas fontes de recursos para além da gestão da marca Senna (ADRIÃO, 2021 - prelo).

A incidência do IAS na educação brasileira e sua articulação internacional é percebida nas parcerias que estabelece a partir de 2018 com organizações internacionais de países que protagonizam melhores desempenho no PISA (Programa Internacional de Avaliação de Estudantes, na sigla em inglês) coordenado pela OCDE: Singapura e Finlândia. No primeiro caso, o projeto envolve a formação de professores de redes públicas brasileiras para a área de STEM (termo em inglês para o campo do conhecimento composto por Ciências, Matemática, Tecnologia e Engenharia). No segundo caso, envolve uma plataforma incorporada a educação em seu "portfólio". https://www.insper.edu.br/quem-somos/, Acesso fev 2020.

1416 - Rev. Bras. Polít. Adm. Educ. - v. 37, n. 3, p. 1413 - 1440, set./dez. 2021 
de "gamificação, a Seppo, que permite o uso da ferramenta em programas implentados em escolas de todas as regiões do Brasil. Em relação à inserção na política educacional brasileira, estudos anteriores (ADRIÃO e PERONI, 2011) indicavam que, desde a primeira década deste século, o IAS implementa programas que incidem sobre a organização do ensino fundamental em cerca de dois mil municípios em todos os Estados da Federação.

Um último aspecto relativo à inserção do IAS e às suas pautas, expressas nos tweets categorizados, refere-se ao alinhamento com as proposições do Center for Curriculum Redesign (CCR), entidade constituída por organizações internacionais, esferas governamentais, instituições acadêmicas, corporações e organizações sem fins lucrativos. Para Adrião (2018), o CCR propõe alterações globalmente definidas nos currículos e nos programas de ensino com vistas à articulação entre conhecimentos, habilidades, valores e metacognição, em síntese, propondo a adoção das habilidades socioemocionais socioemocionais defendidas pelo IAS.

Vinculado à pesquisa financiada pela Fapesp, o artigo está organizado em quatro partes principais. $\mathrm{Na}$ sequência destas notas introdutórias, o texto apresenta a metodologia da investigação; as tendências dos tweets do IAS sistematizadas em categorias que emergiram da análise de conteúdo, os usuários (indivíduos e organizações) mais frequentes nos tweets e as agendas ou pautas veiculadas. Por fim, em sua última parte apresenta as principais conclusões.

\section{METODOLOGIA}

$\mathrm{O}$ artigo tem por base a análise dos dados do Twitter publicados pela conta oficial Twitter do Instituto Ayrton Senna (@instayrtonsenna). A conta do Twitter do IAS, criada em novembro de 2009, segue 174 outras contas e tem 142 mil seguidores, dados que informam as conexões estabelecidas pelo Instituto. A mensagem de apresentação de sua conta - "Há mais de 20 anos transformando vidas com educação de qualidade" - ilustra o perfil público da organização. A análise centra-se no que denominamos tendências, estas são identificadas e apresentadas por meio de categorias derivadas da Análise de Conteúdo, dos usuários mencionados nos tweets e das agendas veiculadas em sua conta oficial do Twitter.

Por intermédio de procedimentos sistemáticos e objetivos de descrição do conteúdo das mensagens, busca-se inferir conhecimentos relativos às condições de produção e recepção destas mensagens "para evidenciar os indicadores que permitam inferir sobre uma outra realidade que não a da mensagem" (BARDIN, 2007: p. 37- 41). 
Se existe uma longa tradição no uso da Análise de Conteúdo (AC) em estudos no campo das comunicações, como a mídia impressa, e de pesquisas documentais (BARDIN, 2007), seu uso na análise de redes sociais é ainda escasso. À relevância de estudos sobre o uso do Twitter em investigações relativas à atuação de atores políticos nacionais e internacionais e suas negociações e estratégias de influência na política educacional, agregam-se razões pragmáticas para que os dados desta plataforma sejam particularmente bem adatados à metodologia da AC, como proposto no presente estudo. Este aspecto advém do fato de que tais dados estão publicamente disponíveis, enquanto em outros meios de comunicação a visibilidade da informação frequentemente depende da permissão de acesso por parte do usuário. Além disso, os dados do Twitter podem ser descarregados em massa por meio da Interface de Programação de Aplicações (API, pela sigla em ingles), através da qual se pode recuperar um conjunto de dados por ano e grande quantidade de valores associados ao Twitter (dia, hora, hiperligações, usuários mencionados, entre outros), o que significa que um grande conjunto de dados pode ser reunido em relativamente pouco tempo.

Assim, ancorados na AC e em concordância com Oliveira et al (2003), para quem se trata de procedimento metodológico confiável para identificação das linhas mestras de um texto, analisaram-se os tweets com vistas a obter informações sobre seu conteúdo temático.

Para este artigo, os dados foram descarregados da conta do IAS no Twitter, utilizando a versão profissional do software NodeXL para o período em análise: 11 de abril de 2013 a 30 de agosto de 2020. Uma vez que a rede social Twitter limita o acesso ao histórico de tweets não foi possível obter dados anteriores a 11 de abril de 2013.

Através da API do Twitter, acionada entre maio a dezembro de 2020, foi possível ter acesso a 3.022 tweets da conta do Instituto Ayrton Senna, 54 dos quais em língua inglesa, todos constituiram o corpus documental inicialmente analisado. Entretanto, tendo em vista que o objetivo deste artigo é caracterizar as iniciativas do IAS, as replicações de tweets de outros atores (Retweets) e as respostas do Instituito a perguntas de outrem foram excluídas da análise posto não refletirem a iniciativa do IAS. Considerando estes critérios, selecionaram-se 2.968 mensagens.

Para este feito, após leitura dos 2.968 tweets selecionados, considerados na unidade de contexto, prestou-se atenção a características qualitativas envolvidas nas temáticas abordadas nos textos dos tweets. Desta reflexão originaram-se 41 categorias decorrentes das unidades de registro organizadas em tabela elaborada para este feito. A maior parte dos tweets (93\%) foram classificados em mais 
de uma categoria, uma vez que o texto da mensagem articulava aspectos que preenchiam os requisitos para sua inclusão em mais de uma categoria. Neste caso, identificou-se o que se designa como co-ocorrência das unidades de registro, ou seja "a presença simultânea de duas ou mais unidades de registo numa unidade de contexto [frase ou parágrafo que permite compreender a significação da unidade de registo]" (BARDIN, 2007: p. 105). Este tratamento foi realizado pelos autores que codificaram as 2968 mensagens a partir do "tema" do conteúdo de cada mensagem tendo em consideração os princípios apontados por BARDIN (2007): exclusão mútua, homogeneidade, pertinência, objetividade e fidelidade.

Como método complementar à AC, utilizamos a análise automática de frequência por meio do software NodeXL Pro para detectar as palavras que ocorreram com maior frequência nos tweets, incluindo os usuários mencionados e as hashtags ${ }^{4}$. A análise automática de frequência consiste na identificação e quantificação pelo software das palavras organizando-as em função de valores estatísticos. Esta análise permitiu detectar tendências nas unidades de contexto nem sempre identificadas em procedimentos realizados exclusivamente por pessoas (THELWALL; CUGELMAN, 2017).

Devido ao Twitter ser uma plataforma de microblogging, as mensagens adquirem características específicas, isto é, são mais diretas e simples (WELLER; BRUNS; BURGESS; MAHRT et al., 2014), quando comparadas a outras redes sociais, originando um número elevado de co-ocorrência das unidades de registo identificadas pela análise de conteúdo. Tendo em consideração este aspecto, os autores decidiram utilizar a análise de rede para perceber melhor a relação entre as categorias que apresentaram co-ocorrência nas unidades de registo. $\mathrm{O}$ procedimento foi simples: se duas categorias são associadas a um mesmo tweet (co-ocorrência), cria-se uma conexão. Se uma mesma categoria co-ocorre em um segundo tweet, a conexão entre eles é reforçada. Estes dados são incorporados em uma tabela denominada matriz de adjacência que recebeu tratamento de estatístico pelo software, resultando na representação gráfica (Figura 2).

A representação gráfica das redes consiste em um conjunto de vértices ou nós conectados por linhas. Cada vértice expressa uma categoria da análise de conteúdo e cada linha representa uma relação (co-ocorrência) entre dois vértices. A espessura dos vértices é proporcional ao número de relações entre as diferentes categorias. Utilizamos o software NodeXL Pro para esta construção. O nível de relevo de cada categoria, considerado em função da matriz de adjacência, foi testado com a closeness centrality (proximidade que um vértice assume

\footnotetext{
4 Estratégia utilizada nas redes sociais inserindo o símbolo \# antes da palavra, frase ou expressão, para que o termo associado a um tópico possa ser mais facilmente encontrado e o seu conteúdo impacte mais pessoas de modo a ampliar sua visibilidade
} 
relativamente aos outros da rede) e a betweenness centrality (fornece o grau em que os vértices se encontram situados nos caminhos mais curtos entre pares de outros vértices, encontra-se num ponto de passagem obrigatório para outros vértices, controlando assim o fluxo de informação) (HANSEN; SHNEIDERMAN; SMITH; HIMELBOIM, 2020).

\section{TENDÊNCIAS DOS TWEETS DO INSTITUTO AYRTON SENNA}

Neste tópico iremos explorar as tendências dos tweets do IAS. Para tanto, observamos no Quadro-5 as 42 categorias sistematizadas na análise de conteúdo organizadas por ordem alfabética, a respectiva frequência global e a frequência por ano civil. Ao final também são analisadas as tendências das co-ocorrência das unidades de registo para que se fez uso da análise de redes conforme figura 2.

\section{TENDÊNCIAS GLOBAIS DOS TWEETS DO INSTITUTO AYRTON SENNA}

Quando realizamos uma análise geral dos resultados obtidos, verificamos que das categorias derivadas de mensagens com 100 ou mais unidades de registo (figura 1) se destacam quatro. A primeira categoria, Promoção dos programas educacionais / atividades / resultados do Instituto Ayrton Senna apresenta mais que o triplo de unidades de registo (1653) em relação à segunda categoria Lembrança dos feitos de Ayrton Senna (505). Na sequência indica-se a categoria Angariação de fundos (416) seguida de Promoção da revistal tirinhas/ jogo Senninha (108). Indentificamos que o IAS priorizou mensagens relacionadas à disseminação de sua atuação na educação, à sua visibilidade e à promoção da "causa" do Instituto Ayrton Senna e da marca comercial associada à imagem do Piloto. 


\section{Figura 1 - Categorias com 100 ou mais unidades de registo no Twitter do IAS - 2013-2020 em ordem crescente.}

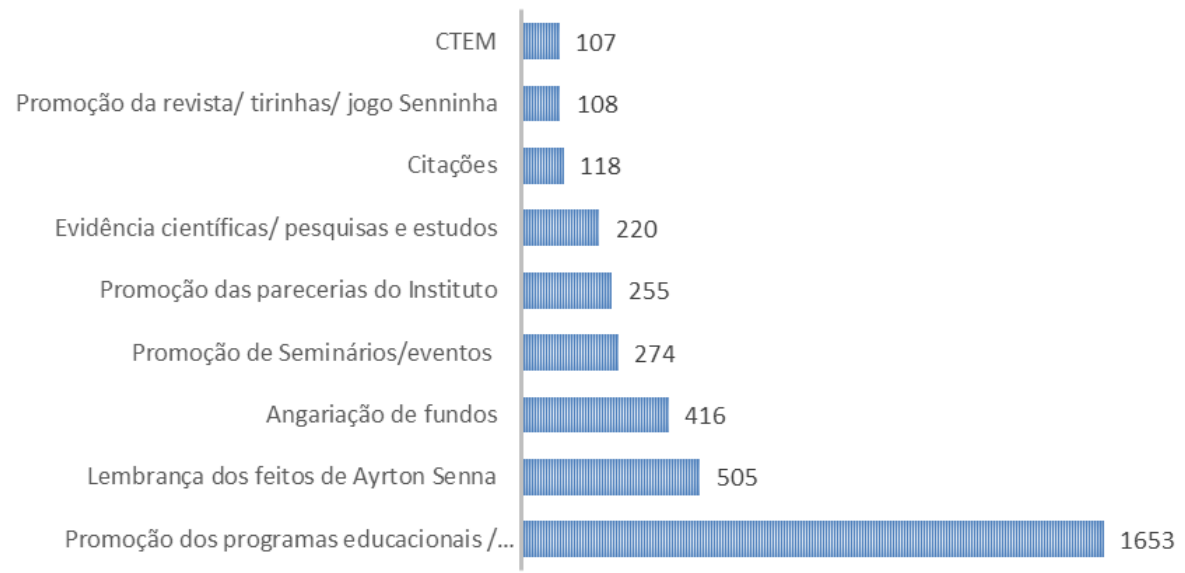

Fonte: elaborada pelos autores

Não obstante, é importante ter em consideração que 54\% dos tweets da categoria Lembrança dos feitos de Ayrton Senna foram registradas nos anos de 2013 e 2014, verificando-se uma simbiose entre o legado do piloto e as atividades/ resultados do IAS que se dissipam a partir de 2015. Este fato parece estar relacionado com a criação em 2014 do perfil oficial no Twitter sobre Ayrton Senna e com a necessidade de potencializar a marca. Vale lembrar que ainda a partir de 2012, o IAS se torna a primeira organização brasileira na NetFWD (Net Forward), rede global de fundações dedicadas a promover mecanismos para aferição do impacto social do que apoiam.

As demais categorias com 100 ou mais unidades de registo, indicadas na Figura-1, parecem indicar as prioridades relativas à política educacional que o IAS dissemina pelo Twitter. Nesses termos, destacam-se temas inerentes à defesa da ciência, tecnologia, engenharia e matemática (CTEM ou STEM) como orientadores de reformas curriculares, à divulgação de citações ou frases de autores associadas às posições sobre a educação brasileira disseminadas pelo IAS e o apoio ao que designa como evidências científicas traduzidas em resultados de pesquisas ou estudos para legitimar as pautas defendidas pelo Instituto.

Assim, tal como a estratégia de governança de várias organizações a nível internacional (KNUTSSON; LINDBERG, 2020), o IAS assume algumas características pós-políticas ao tentar despolitizar as posições defendidas e os alinhamentos efetivados em âmbito nacional e internacional com atores 
posicionados. Para o público em geral, as propostas, ações e as políticas implantadas pelo IAS nos sistemas públicos de ensino no Brasil são cientificamente justificadas por estudos e apoiadas em evidências que resultam de estudos desenvolvidos por consultores contratados pelo próprio IAS ou elaborados por organizações e pesquisadores parceiros.

Esse modusoperandiassocia-se à lógica instituída pelo segmento denominado de filantrocapitalistas ou em inglês venture philanthropy (BISHOP e GREEN, 2015) venture filantropia em resposta ao Índice de Sustentabilidade Empresarial (ISE), ferramenta lançada em 2005 pelo International Finance Corporation (IFC), braço financeiro do Banco Mundial, e exigida para análise das empresas listadas em Bolsas de Valores 5 . O ISE estimulou a criação de Gestoras de Investimentos Sociais, que aplicam a lógica do mercado financeiro para selecionar investimentos sociais de resultados, de maneira que evidências sobre os resultados de suas ações passam a ser demandandas pelos donantes.

Os tweets que se referem a CTEM promovem iniciativas relacionadas ao uso de tecnologia e redes sociais na sala de aula, a programas de letramento em programação informática e á inicitiva EduLab21.

Apesar da categoria Instituto e as Org. Internacionais [25] não se destacar na quantificação das unidades de registo - conforme Quadro5, considerou-se dar-lhe ênfase nesta análise global, uma vez que a chancela que o IAS recebeu da UNESCO, a Cátedra de Educação e Desenvolvimento Humano, e a parceria com a OCDE são utilizadas nas mensagens que suportam esta categoria para legitimar as ações e as opções tomadas. Como ilustram os exemplos abaixo, a Cátedra da UNESCO é mencionada para legitimar o IAS de uma forma global, enquanto a OCDE para reafirmar posições sobre a relevância das habilidades socioemocionais, do CTEM e de resultados acadêmicos.

Instituto Ayrton Senna (@instayrtonsenna)."Você sabia que o Instituto recebeu, da UNESCO, uma chancela concedida de forma inédita a uma ONG? http://t. co/WlmEFH9JxD“. 15/04/2013, 14:22. Tweet.

Instituto Ayrton Senna (@instayrtonsenna). “Parceria entre Instituto e OCDE estudará habilidades nãocognitivas em 50 mil estudantes da rede pública do RJ. Veja: http://t.co/vDRPOirREx“. 11/06/2013, 16:59. Tweet.

Instituto Ayrton Senna (@instayrtonsenna).“O @ instayrtonsenna foi citado em um novo estudo da OCDE! Saiba mais: http://t.co/VItyTKXdtB http://t.co/ HQL7kMPBCb“. 04/06/2013, 22:23. Tweet.

5 http://www.b3.com.br/pt_br/market-data-e-indices/indices/indices-de-sustentabilidade/indicede-sustentabilidade-empresarial-ise.htm 
Instituto Ayrton Senna (@instayrtonsenna). "Reunião internacional na OCDE debate competências cognitivas e socioemocionais, com presença do @ instayrtonsenna! http://t.co/DykwpYAuB2“. 20/07/2013, 23:55. Tweet.

Instituto Ayrton Senna (@instayrtonsenna). "Fomos a $1^{\circ}$ ONG no Brasil a receber a cátedra de Educação da @UNESCOBrasil! https://t.co/EppMn7uv5S \#EducaçãoDoFuturo https://t.co/GUhHue8o7F“. 24/10/2015, 13:00. Tweet.

Instituto Ayrton Senna (@instayrtonsenna).“@OECD O Brasil é destaque entre as experiências inovadoras mapeadas pela organização ao redor do mundo e o projeto é parte das iniciativas do Instituto Ayrton Senna. Quer saber mais? Aguarde novidades em nossas redes! O relatório completo você encontra aqui: https://t.co/llXn1Gpzl3“. 24/09/2019, 20:30. Tweet.

Instituto Ayrton Senna (@instayrtonsenna). “Os indicadores da educação, como o último Programa Internacional de Avaliação de Alunos, o PISA, mostra que o Brasil ainda tem grandes desafios pela frente. Para ajudar, o@instayrtonsenna divulgou um diagnóstico educacional, com foco em 2 fatores: Escolas e Professores. https://t.co/eqj2JPjdpX“. 09/12/2019, 13:08. Tweet.

Além da análise das unidades de registros, sistematizadas nas categorias tratadas, o estudo considerou a frequência identificada pelo NodeXL Pro com que palavras, usuários e hashtags se apresentaram nos tweets, informações indicadas nos Quadros 1, 2 e 3. Devido a limitações de espaço neste artigo, mostramos apenas os dez primeiros resultados organizados hierarquicamente em ordem decrescente. Esta análise permitiu identificar que as palavras com maior frequência são, pela ordem: Senna, educação, Ayrton, Instituto, crianças, Brasil, alunos, hoje, jovens, escola e ensino. As palavras estão diretamente relacionadas ao campo de atuação do IAS - educação, escola e ensino - e ao público-alvo de suas iniciativas - crianças, alunos e jovens. 


\section{Quadro 1 - Palavras mais mencionadas nos tweets do IAS e respectiva frequência- 2013/2020}

\begin{tabular}{|c|c|}
\hline Palavra & Frequência \\
\hline Senna & 696 \\
\hline Educação & 653 \\
\hline Ayrton & 425 \\
\hline Instituto & 358 \\
\hline Crianças & 213 \\
\hline Brasil & 165 \\
\hline Alunos & 154 \\
\hline Hoje & 146 \\
\hline Jovens & 141 \\
\hline Escola & 118 \\
\hline Ensino & 118 \\
\hline
\end{tabular}

Fonte: elaborado pelos autores

Importa destacar que a palavra hoje surge com frequência nos tweets, buscando imprimir um sentido de atualidade e ou de novidade como apelo aos leitores/ seguidores.

No que concerne aos usuários mencionados, destacam-se seis organizações. As três mais frequentes são: Porvir- plataforma de conteúdos e mobilização sobre inovações educacionais - seguida do BH Shopping e Iguatemi Ribeirão Preto, duas das maiores empresas de Shopping Centers do país. Em relação ao Porvir as menções mais frequentes entre 2014 e 2016 referem-se à inovação em educação, ao tema das competências socioemocionais ou à criação de materiais pedagógicos, como se vê nos textos selecionados em função de sua exemplaridade:

Instituto AyrtonSenna (@instayrtonsenna)."Estamosno "O Futuro se Aprende”, evento do@porvir_em parceria conosco, para discutir \#socioemocionais http://t.co/xeNAb3SeI8“. 23/09/2014, 17:35. Tweet.

Instituto Ayrton Senna (@instayrtonsenna). "E lançamos um site especial sobre competências socioemocionais em parceria com o@porvir_http://t.co/ Y8cVHQNw0b \#RetrospectivaIAS”. 26/01/2015, 22:08. Tweet. 
Instituto Ayrton Senna (@instayrtonsenna). “Como utilizar tecnologia nas escolas públicas? O @ porvir_ lançou um guia completo sobre o tema, dá uma olhada: https://t.co/iBh9HzyL92“. 01/09/2015, 14:41. Tweet.

Instituto Ayrton Senna (@instayrtonsenna). “A escola dos sonhos foi enfim definida! \#EducaçãoDoFuturo Veja o resultado da pesquisa do @porvir_ https://t.co/SNIpHVlx94". 22/09/2016, 22:35. Tweet.

No que concerne ao BH Shopping e ao Iguatemi Ribeirão Preto, os tweets relacionam-se à promoção de eventos associados ao legado de Ayrton Senna, como por exemplo:

Instituto Ayrton Senna (@instayrtonsenna). “Hoje começou a exposição ‘Senna Emotion - 20 Anos de Legado’no@iguatemirib, participe! \#SennaSempre http://t.co/fDGvIqnkEM“. 02/05/2014, 01:31. Tweet.

Instituto Ayrton Senna (@instayrtonsenna). "Daqui a pouco inauguraremos a exposição "Senna na Cabeça e no Coração" no @bhshopping, com 20 capacetes customizados por personalidades!". 05/08/2014, 21:58. Tweet.

Ainda em relação aos usuários institucionais com maior frequência encontram-se três organizações de base empresarial e protagonistas nos processos de privatização da educação pública por meio da implantação de políticas que esvaziam a ação estatal, como indicado em estudos de Freitas (2012); Adrião e Domiciano (2018); Martins (2016) são elas: a Fundação Lemann (nos anos de 2014, 2019 e 2020), a Fundação Telefônica Brasil (no ano de 2014) e o Todos pela Educação (nos anos de 2014 e 2019).

As Fundações são referidas, principalmente no ano de 2014, na promoção de iniciativas de letramento em programação informática, como ilustram os exemplos abaixo:

Instituto Ayrton Senna (@instayrtonsenna). “Olá!@fundacaolemann Eles desenvolveram tecnologias que transformaram os hábitos da sociedade". 04/12/2014, 14:00. Tweet.

Instituto Ayrton Senna (@instayrtonsenna). “Sim,@fundacaolemann! Nós faremos uma \#HoraDoCodigo por aqui na próxima semana. Mandaremos fotos! :) @FT_Brasil”. 04/12/2014, 16:05. Tweet.

Instituto Ayrton Senna (@instayrtonsenna). "E contam com parceiros e apoiadores como nós. @fundacaolemann e @FT_Brasil :) \#HoraDoCodigo”. 04/12/2014, 16:30. Tweet. 
Já a UNESCO (no ano de 2015, 2016 e 2019) e o Todos pela Educação (no ano de 2015 e 2019) são mencionadas como participantes em eventos organizados pelo IAS ou quando o Instituto replica eventos dessas organizações envolvendo temas relacionados a aspectos das reformas educativas que contaram com a incidência direta do IAS, como se vê:

Instituto Ayrton Senna (@instayrtonsenna). “Hoje o café da manhã é com o @TodosEducacao e começa com novas ideias para melhorar a \#Educação no Brasil, acompanhe! http://t.co/OhxRFuUE0N“". 14/10/2014, 13:23. Tweet.

Instituto Ayrton Senna (@instayrtonsenna)."Estiveram aqui conosco a Secretaria de Educação de Pernambuco, @TodosEducacao, @ItauSocial, SEDAC, @ fundacaoseade e a @MindLabBR”.16/03/2015, 19:15. Tweet.

Instituto Ayrton Senna (@instayrtonsenna)."Recebemos a @UNESCOBrasil para uma conversa sobre educação integral. Já conhece esse conceito? http://t. co/XtPFa9Jw7r http://t.co/6EXVOLenAA“. 13/03/2015, 20:57. Tweet.

Instituto Ayrton Senna (@instayrtonsenna).“A @UnescoBrasil está aqui para trocar conhecimentos e transformar a educação do país! \#EducaçãoDoFuturo http://t.co/fuTRbIZh9o“. 30/06/2015, 14:23. Tweet.

Importa reter que o IAS foi a primeira organização nãogovernamental a integrar, desde 2003, uma Cátedra associada à UNESCO.

\section{Quadro 2 - Usuários do Twitter mais mencionados nos tweets do Instituto Ayrton Senna e respectiva frequência}

\begin{tabular}{|l|c|}
\hline Usuários & N \\
\hline @instayrtonsenna [Instituto Ayrton Senna] & 187 \\
\hline @porvir_[Porvir] & 28 \\
\hline @fundacaolemann [Fundação Lemann] & 28 \\
\hline @ayrtonsenna [Ayrton Senna] & 21 \\
\hline @ft_brasil [Fundação Telefônica Brasil] & 18 \\
\hline @bsenna [Bruno Senna] & 14 \\
\hline @bhshopping [BH Shopping] & 12 \\
\hline @todoseducacao [Todos pela Educação] & 12 \\
\hline @iguatemirib [lguatemi Ribeirão Preto] & 12 \\
\hline @unescobrasil [UNESCO Brasil] & 10 \\
\hline
\end{tabular}

Fonte: elaborado pelos autores 
No que concerne aos dez hashtags mais usados, dois dizem diretamente respeito à promoção do IAS e ao legado de Ayrton Senna (\#institutoayrtonsenna, \#ayrtonsenna e \#doeletras), dois buscam catapultar programas educativos implementados pelo IAS (\#nota10 e \#educacao) e cinco disseminam ideiaschaves derivadas de prioridades para a educação pública brasileira definidas pelo IAS, neste caso associadas ao que designam como inovações (\#educaçãodofuturo, \#ciênciaparaeducação e \#horadocodigo), ou à promoção das CTEM (\#ciênciaparaeducação e \#horadocodigo).

A análise global das diferentes categorias e a análise automática de frequência de palavras e expressões derivadas do software NodeXL Pro permitem concluir que as principais funções da conta de Twitter do IAS no período foram amplificar a visibilidade dos seus programas, potencializar a angariação de fundos, e promover parceiros específicos.

\section{Quadro 3 - Hashtags mais mencionados nos tweets do} Instituto Ayrton Senna e respetiva frequência - 2013/2020

\begin{tabular}{|l|c|}
\hline Hashtags & N \\
\hline \#educaçãodofuturo & 483 \\
\hline \#educação & 134 \\
\hline \#sennasempre & 107 \\
\hline \#senna & 93 \\
\hline \#ciênciaparaeducação & 75 \\
\hline \#institutoayrtonsenna & 65 \\
\hline \#doeletras & 49 \\
\hline \#nota10 & 37 \\
\hline \#ayrtonsenna & 36 \\
\hline \#horadocodigo & 35 \\
\hline
\end{tabular}

Fonte: elaborado pelos autores 


\section{TEMAS FREQUENTES POR ANO CIVIL - AS POSIÇÕES DO IAS EM PERSPECTIVA}

Para perceber as tendências implícitas às mensagens relativas à política educacional propagadas pelo IAS, analisamos também as categorias mais frequentes por ano civil. Para tanto, foram excluídas as categorias ${ }^{6}$ que tratam da visibilidade ou da promoção do IAS.

O Quadro 4 apresenta, com base na frequência com que foram repercutidas, as duas categorias de maior ocorrência em cada ano do período analisado associadas diretamente à educação pública.

\section{Quadro 4 - Categorias com maior frequência por ano civil excluídas as que não se referem à educação- 2013/2020}

\begin{tabular}{|c|l|}
\hline 2013 & $\begin{array}{l}\text { - Educação/ ensino de qualidade/ referência [12] } \\
\text { - Rede/ Educação pública [11] }\end{array}$ \\
\hline 2014 & $\begin{array}{l}\text { - Rede/ Educação pública [11] } \\
\text { - Educação/ ensino de qualidade/ referência [8] }\end{array}$ \\
\hline 2015 & $\begin{array}{l}\text { - Evidência científicas [106] } \\
\text { - Evidência científicas/ citações [89] }\end{array}$ \\
\hline 2016 & $\begin{array}{l}\text { - Citações [58] } \\
\text { - CTEM [45] }\end{array}$ \\
\hline 2017 & $\begin{array}{l}\text { - Citações [31] } \\
\text { - Evidência cientificas/ pesquisas e estudos [4] }\end{array}$ \\
\hline 2018 & $\begin{array}{l}\text { - CTEM [22] } \\
\text { - Educação integral e Colaboração/ ligação com o governo [7] }\end{array}$ \\
\hline 2019 & $\begin{array}{l}\text { - Evidência cientificas/ pesquisas e estudos [62] } \\
\text {-Alfabetização [27] }\end{array}$ \\
\hline 2020 & $\begin{array}{l}\text { - Conselhos/ atividades relacionadas com o período pandemia/ pós-pandemia [44] } \\
\text { - Habilidades/ competências socioemocionais [26] }\end{array}$ \\
\hline
\end{tabular}

Fonte: elaborado pelos autores

O Quadro 4 apoia-se nas informações sistematizadas no Quadro 5 e nos permite visualizar as alterações na agenda de temas repercutidos pelo IAS, isto porque, vale lembrar, o Twitter tem sido adotado pelas organizações para rapidamente disseminar ideias sínteses relacionadas a posições estratégicas. Assim, em relação às tendências por ano civil, constata-se que nos anos 2013 e 2014 as categorias são coincidentes, mas não voltam a ganhar relevância nos

6 Angariação de fundos; Atividades/ feitos da Presidente do Instituto Ayrton Senna; Lembrança dos feitos de Ayrton Senna; Promoção dos programas educacionais / atividades / resultados do Instituto Ayrton Senna; Promoção da revista/ tirinhas/ jogo Senninha e Promoção das parecerias do Instituto. 
anos seguintes. O mesmo não acontece nos anos de 2015 a 2019 período no qual se verifica que categorias Evidência científicas/ pesquisas e estudos, CTEM e citações são recorrentes.

Já para o ano de 2020, e muito devido à pandemia do COVID 19, assistimos à emersão da categoria Conselhos/ atividades relacionadas com o período pandemia/ pós-pandemia e uma maior preponderância da categoria competências socioemocionais, que aparece pela primeira vez em 2014 e mesmo, sendo idenficada ao longo do período, sua frequência foi bastante variável. De notar ainda que as alterações temáticas dos tweets coincidem com alterações na estrutura do IAS, principalmente com a entrada Mozart Neves Ramos como diretor de Articulação e Inovação e com Paes de Barros como economista-chefe ${ }^{7}$.

Indica-se tambémqueas tendências dos tweets encontramcorrespondência com a articulação do IAS e agências internacionais, servindo como espécie de plataforma para informar a sua incidência na educação brasileira. Se entre 2013 e 2014 a maioria das mensagens referia-se à rede/ educação pública; a partir de 2014, destaca-se a presença da OCDE associada às categorias CTEM; evidências científicas, resultados acadêmicos e competências socioemocionais. Como dito, a UNESCO é referida para informar a chancela desta organização internacional ao IAS, fato até então inédito para as organizações nãogovernamentais, bem como para promover relatórios ou eventos.

\section{Quadro 5 - Categorias de análise dos tweets e respectiva frequência por ordem alfabética - 2013-2020}

\begin{tabular}{|l|l|c|c|c|c|c|c|c|c|c|}
\hline \multicolumn{1}{|c|}{ Categoria } & \multicolumn{1}{|c|}{ Descrição dos tweets } & Total & 2013 & 2014 & 2015 & 2016 & 2017 & 2018 & 2019 & 2020 \\
\hline Alfabetização & referência à alfabetização & 46 & 4 & 2 & 4 & 4 & 11 & 0 & 27 & 4 \\
\hline $\begin{array}{l}\text { Alimentação } \\
\text { saudável }\end{array}$ & referência à alimentação saudável & 2 & 0 & 0 & 2 & 0 & 0 & 0 & 0 & 0 \\
\hline $\begin{array}{l}\text { Ambiente e } \\
\text { sustentabilidade }\end{array}$ & $\begin{array}{l}\text { referência ao ambiente e à } \\
\text { sustentabilidade }\end{array}$ & 5 & 4 & 0 & 0 & 0 & 0 & 0 & 1 & 0 \\
\hline $\begin{array}{l}\text { Angariação de } \\
\text { fundos }\end{array}$ & $\begin{array}{l}\text { referência a campanhas, iniciativas } \\
\text { ou produtos para angariar fundos } \\
\text { para o instituto }\end{array}$ & 416 & 116 & 117 & 95 & 44 & 4 & 0 & 33 & 5 \\
\hline $\begin{array}{l}\text { Atividades/ } \\
\text { feitos da } \\
\text { Presidente do } \\
\text { Instituto Ayrton } \\
\text { Senna }\end{array}$ & $\begin{array}{l}\text { referência a frases, a prêmios, } \\
\text { menções honrosas e a atividades } \\
\text { desenvolvidas pela Presidente do } \\
\text { IAS Viviane Senna }\end{array}$ & 70 & 7 & 14 & 31 & 2 & 2 & 0 & 8 & 6 \\
\hline
\end{tabular}

\footnotetext{
7 De destacar que esta designação evoca o Banco Mundial, uma vez que esta instituição tem o cargo de economista chefe. No caso do Banco Mundial, o economista chefe é responsável por fornecer liderança e orientação intelectual à estratégia geral de desenvolvimento internacional e por definir a agenda de pesquisa econômica, nos níveis global, regional e nacional.
} 


\section{Quadro 5 - Categorias de análise dos tweets e respectiva frequência por ordem alfabética - 2013-2020}

\begin{tabular}{|c|c|c|c|c|c|c|c|c|c|c|}
\hline Categoria & Descrição dos tweets & Total & 2013 & 2014 & 2015 & 2016 & 2017 & 2018 & 2019 & 2020 \\
\hline $\begin{array}{l}\text { Base nacional } \\
\text { curricular } \\
\text { comum }\end{array}$ & $\begin{array}{l}\text { referência à Base nacional curricular } \\
\text { comum }\end{array}$ & 14 & 0 & 0 & 1 & 4 & 3 & 4 & 2 & 2 \\
\hline Citações & $\begin{array}{l}\text { citam frases de pessoas famosas } \\
\text { ou de personalidades relacionadas } \\
\text { a educação }\end{array}$ & 118 & 0 & 0 & 28 & 58 & 31 & 1 & 0 & 0 \\
\hline $\begin{array}{l}\text { Colaboraçãol } \\
\text { ligação com o } \\
\text { governo }\end{array}$ & $\begin{array}{l}\text { referência à ligação e/ ou } \\
\text { colaboração com o Governo da } \\
\text { União }\end{array}$ & 9 & 0 & 0 & 0 & 0 & 0 & 7 & 2 & 0 \\
\hline $\begin{array}{l}\text { Conselhos/ } \\
\text { atividades } \\
\text { relacionadas } \\
\text { com o período } \\
\text { pandemia/ pós- } \\
\text { pandemia }\end{array}$ & $\begin{array}{l}\text { referência a conselhos e/ ou } \\
\text { atividades relacionadas ao perído } \\
\text { pandemia e/ ou pós-pandemia }\end{array}$ & 44 & 0 & 0 & 0 & 0 & 0 & 0 & 0 & 44 \\
\hline $\begin{array}{l}\text { Criatividade/ } \\
\text { pensamento } \\
\text { crítico }\end{array}$ & $\begin{array}{l}\text { referência à importância da } \\
\text { criatividade e/ ou de desenvolver o } \\
\text { pensamento crítico }\end{array}$ & 31 & 1 & 2 & 2 & 1 & 1 & 0 & 2 & 22 \\
\hline $\begin{array}{l}\text { CTEM - } \\
\text { Ciência, } \\
\text { Tecnologia, } \\
\text { Engenharia e } \\
\text { Matemática }\end{array}$ & $\begin{array}{l}\text { referência à CTEM - Ciência, } \\
\text { Tecnologia, Engenharia e Matemática }\end{array}$ & 107 & 8 & 0 & 18 & 45 & 3 & 22 & 7 & 4 \\
\hline $\begin{array}{l}\text { Desafios da } \\
\text { educação }\end{array}$ & $\begin{array}{l}\text { referência aos desafios da educação } \\
\text { no Brasil }\end{array}$ & 1 & 1 & 0 & 0 & 0 & 0 & 0 & 0 & 0 \\
\hline $\begin{array}{l}\text { Direito à } \\
\text { educação / } \\
\text { Educação como } \\
\text { um direito }\end{array}$ & $\begin{array}{l}\text { referência ao direito à educação e } \\
\text { da perspetiva da educação como } \\
\text { um direito }\end{array}$ & 4 & 0 & 0 & 0 & 3 & 1 & 0 & 1 & 0 \\
\hline $\begin{array}{l}\text { Rede/ Educação } \\
\text { pública }\end{array}$ & $\begin{array}{l}\text { referência à educação pública ou a } \\
\text { uma rede pública de educação }\end{array}$ & 31 & 11 & 8 & 7 & 4 & 0 & 0 & 1 & 0 \\
\hline $\begin{array}{l}\text { Economial } \\
\text { finanças }\end{array}$ & $\begin{array}{l}\text { referência à relação da economia e/ } \\
\text { ou das finanças com a educação }\end{array}$ & 2 & 0 & 0 & 0 & 0 & 0 & 0 & 0 & 2 \\
\hline $\begin{array}{l}\text { Educação } \\
\text { integral }\end{array}$ & $\begin{array}{l}\text { referência à importância da educação } \\
\text { integral }\end{array}$ & 32 & 0 & 0 & 2 & 5 & 1 & 7 & 11 & 6 \\
\hline $\begin{array}{l}\text { Educação/ } \\
\text { ensino de } \\
\text { qualidade/ } \\
\text { referência }\end{array}$ & $\begin{array}{l}\text { referência à educação de qualidade } \\
\text { ou ensino de qualidade ou ensino de } \\
\text { referência }\end{array}$ & 46 & 12 & 8 & 12 & 7 & 0 & 1 & 6 & 0 \\
\hline $\begin{array}{l}\text { Ensino } \\
\text { fundamental }\end{array}$ & referência ao ensino fundamental & 14 & 1 & 1 & 1 & 1 & 0 & 0 & 8 & 2 \\
\hline Ensino médio & referência ao ensino médio & 42 & 1 & 4 & 14 & 6 & 1 & 2 & 14 & 0 \\
\hline Ensino Superior & referência ao ensino superior & 1 & 0 & 0 & 0 & 1 & 0 & 0 & 0 & 0 \\
\hline Esporte & referência ao esporte & 18 & 0 & 5 & 1 & 8 & 3 & 0 & 1 & 0 \\
\hline $\begin{array}{l}\text { Evidência } \\
\text { científicas/ } \\
\text { pesquisas e } \\
\text { estudos }\end{array}$ & $\begin{array}{l}\text { referência a evidências científicas, a } \\
\text { pesquisas ou estudos para suportar } \\
\text { um determinado tipo de posição ou } \\
\text { para veicular uma ideia }\end{array}$ & 220 & 3 & 7 & 106 & 17 & 4 & 5 & 62 & 16 \\
\hline $\begin{array}{l}\text { Foco nos } \\
\text { resultados da } \\
\text { aprendizagem }\end{array}$ & $\begin{array}{l}\text { referência a que a educação se } \\
\text { deve focar nos resultados da } \\
\text { aprendizagem }\end{array}$ & 2 & 1 & 0 & 0 & 0 & 0 & 0 & 1 & 0 \\
\hline
\end{tabular}




\section{Quadro 5 - Categorias de análise dos tweets e respectiva frequência por ordem alfabética - 2013-2020}

\begin{tabular}{|c|c|c|c|c|c|c|c|c|c|c|}
\hline Categoria & Descrição dos tweets & Total & 2013 & 2014 & 2015 & 2016 & 2017 & 2018 & 2019 & 2020 \\
\hline $\begin{array}{l}\text { Formaçãol } \\
\text { capacitação de } \\
\text { professores }\end{array}$ & $\begin{array}{l}\text { referência à importância da } \\
\text { formação/ capacitação de } \\
\text { professores }\end{array}$ & 23 & 7 & 1 & 6 & 4 & 1 & 2 & 1 & 1 \\
\hline $\begin{array}{l}\text { Habilidades/ } \\
\text { competências para } \\
\text { a vida }\end{array}$ & $\begin{array}{l}\text { referência à importância das } \\
\text { habilidades/ competências para } \\
\text { a vida }\end{array}$ & 5 & 1 & 0 & 3 & 0 & 1 & 0 & 0 & 0 \\
\hline $\begin{array}{l}\text { Habilidades/ } \\
\text { competências para } \\
\text { o sec. XXI }\end{array}$ & $\begin{array}{l}\text { referência às habilidades/ } \\
\text { competências para o sec. XXI }\end{array}$ & 11 & 0 & 1 & 4 & 0 & 1 & 0 & 2 & 3 \\
\hline $\begin{array}{l}\text { Habilidades/ } \\
\text { competências } \\
\text { socioemocionais }\end{array}$ & $\begin{array}{l}\text { referência às habilidades/ } \\
\text { competências socioemocionais }\end{array}$ & 65 & 0 & 1 & 21 & 6 & 2 & 0 & 9 & 26 \\
\hline $\begin{array}{l}\text { Incentivo ao } \\
\text { setor privado na } \\
\text { educação }\end{array}$ & $\begin{array}{l}\text { incentivam o aumento da } \\
\text { participação do setor privado na } \\
\text { educação }\end{array}$ & 2 & 0 & 0 & 0 & 0 & 0 & 0 & 0 & 0 \\
\hline Inglês & $\begin{array}{l}\text { referência à necessidade de } \\
\text { aprender inglês }\end{array}$ & 1 & 0 & 0 & 0 & 0 & 0 & 0 & 1 & 0 \\
\hline $\begin{array}{l}\text { Inovação em } \\
\text { educação }\end{array}$ & referência a inovações em educação & 39 & 0 & 2 & 19 & 8 & 0 & 2 & 4 & 4 \\
\hline $\begin{array}{l}\text { Instituto e as Org. } \\
\text { Internacionais }\end{array}$ & $\begin{array}{l}\text { referência à relação entre o Instituto } \\
\text { e organizações internacionais (ex. } \\
\text { OCDE e UNESCO) }\end{array}$ & 25 & 5 & 4 & 7 & 0 & 1 & 1 & 7 & 0 \\
\hline $\begin{array}{l}\text { Lembrança dos } \\
\text { feitos de Ayrton } \\
\text { Senna }\end{array}$ & $\begin{array}{l}\text { referência aos feitos de Ayrton Senna } \\
\text { recordando o seu legado e/ ou frases }\end{array}$ & 505 & 273 & 208 & 4 & 5 & 5 & 2 & 5 & 3 \\
\hline Meditação & $\begin{array}{l}\text { referência à importância da } \\
\text { meditação }\end{array}$ & 1 & 0 & 0 & 1 & 0 & 0 & 0 & 0 & 0 \\
\hline $\begin{array}{l}\text { Mundo do trabalho/ } \\
\text { empreendedorismo/ } \\
\text { aprendizado mão } \\
\text { na massa }\end{array}$ & $\begin{array}{l}\text { referência ao mundo do trabalho } \\
\text { e/ ou empreendedorismo, e/ ou } \\
\text { aprendizado mão na massa }\end{array}$ & 6 & 2 & 0 & 0 & 0 & 0 & 2 & 0 & 2 \\
\hline $\begin{array}{l}\text { Plano Nacional da } \\
\text { Educação }\end{array}$ & $\begin{array}{l}\text { referência ao Plano Nacional da } \\
\text { Educação }\end{array}$ & 9 & 0 & 1 & 4 & 0 & 1 & 0 & 3 & 0 \\
\hline $\begin{array}{l}\text { Promoção da } \\
\text { leitura/ escrita }\end{array}$ & promoção da leitura e/ ou da escrita & 47 & 6 & 0 & 19 & 16 & 2 & 0 & 4 & 0 \\
\hline $\begin{array}{l}\text { Promoção da } \\
\text { revistal tirinhas/ } \\
\text { jogo Senninha }\end{array}$ & $\begin{array}{l}\text { referência à revista, a jogos ou à } \\
\text { tirinha do Senninha }\end{array}$ & 108 & 43 & 58 & 5 & 2 & 0 & 0 & 0 & 0 \\
\hline $\begin{array}{l}\text { Promoção das } \\
\text { parecerias do } \\
\text { Instituto }\end{array}$ & $\begin{array}{l}\text { promoção de várias organizações } \\
\text { que são parceiras do Instituto }\end{array}$ & 255 & 64 & 85 & 29 & 25 & 6 & 3 & 35 & 8 \\
\hline $\begin{array}{l}\text { Promoção de } \\
\text { datas festivas (dia } \\
\text { da mãe/ jovem / } \\
\text { da leitura / dia do } \\
\text { ambiente) / prêmios }\end{array}$ & $\begin{array}{l}\text { a promoção de datas festivas (dia } \\
\text { da mãel jovem / da leitura / dia do } \\
\text { ambiente) ou prêmios }\end{array}$ & 71 & 9 & 1 & 21 & 18 & 5 & 3 & 9 & 5 \\
\hline
\end{tabular}


Quadro 5 - Categorias de análise dos tweets e respectiva frequência por ordem alfabética - 2013-2020

\begin{tabular}{|l|l|c|c|c|c|c|c|c|c|c|}
\hline \multicolumn{1}{|c|}{ Categoria } & \multicolumn{1}{|c|}{ Descrição dos tweets } & Total & 2013 & 2014 & 2015 & 2016 & 2017 & 2018 & 2019 & 2020 \\
\hline $\begin{array}{l}\text { Promoção de } \\
\text { Seminários/eventos }\end{array}$ & $\begin{array}{l}\text { a promoção de seminários ou } \\
\text { eventos de várias tipologias }\end{array}$ & 274 & 1 & 11 & 89 & 37 & 1 & 28 & 64 & 43 \\
\hline $\begin{array}{l}\text { Promoção dos } \\
\text { programas } \\
\text { educacionais } \\
\text { / atividades / } \\
\text { resultados }\end{array}$ & $\begin{array}{l}\text { promoção dos programas } \\
\text { educacionais, das atividades ou dos } \\
\text { resultados do Instituto }\end{array}$ & 1653 & 213 & 486 & 433 & 180 & 39 & 56 & 156 & 90 \\
\hline
\end{tabular}

Fonte: elaborado pelos autores

\section{TENDÊNCIAS DAS CO-OCORRÊNCIAS DAS UNIDADES DE REGISTRO - O FLUXO DAS MENSAGENS POSTO EM EVIDÊNCIA}

Como referido anteriormente, a análise de redes adotada para os casos de co-ocorrências das categorias da $\mathrm{AC}$ permite visualisar as principais conexões entre as mensagens dos tweets, bem como identificar as mensagens de maior "potência". Lembramos que as categorias de análise inicialmente evidenciadas se matêm, contudo ganham outra evidência uma vez que nos centramos nas que apresentam co-ocorrências.

$\mathrm{Na}$ Figura 2 a representação gráfica da análise de rede aplicada às categorias com co-ocorrências mostra um aglomerado, densamente articulado, composto por 40 categorias, dentre as quais se destacam as representadas pelos maiores nós ou vértices: Promoção dos programas educacionais / atividades / resultados; Evidência científicas / pesquisas e estudos; Promoção de Seminários/ eventos; Promoção das parcerias do Instituto e Habilidades/ competências socioemocionais. 


\section{Figura 2 - Análise de rede das 40 categorias com co-ocorrência}

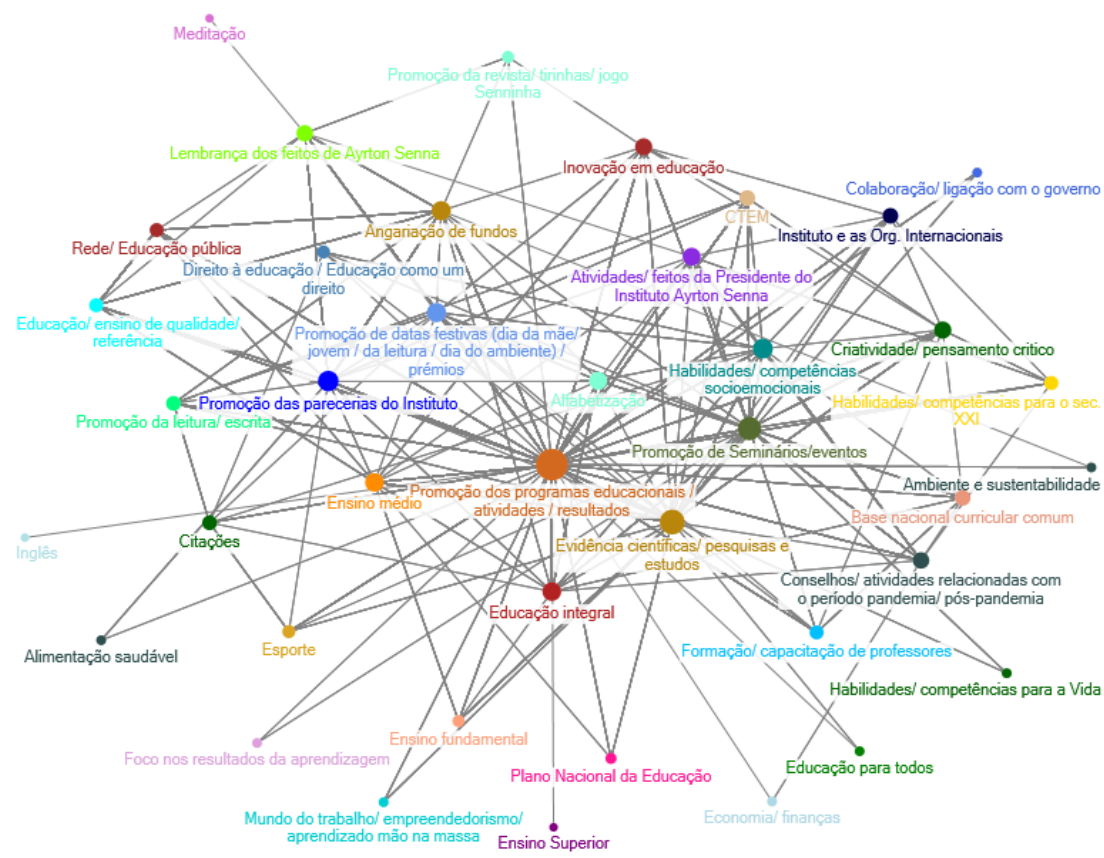

Fonte: elaborado pelos autores

O aglomerado expresso na Figura 2 sugere que certas categorias assumem uma função de maior densidade conectiva que outras, representadas pelos nodos maiores. Esta tendência é confirmada pela closeness centrality average $(0,014)$ a qual sugere que os vértices/categorias estão mais interligados que outras. (HANSEN; SHNEIDERMAN; SMITH; HIMELBOIM, 2020).

A análise da figura 2, combinada com os resultados estatísticos (tabela 1), confirma o percebido pela análise de conteúdo, posto que as principais coocorrências envolvem as cinco categorias da análise de conteúdo que controlam o fluxo de informação (betweenness centrality), as quais versam sobre a visibilidade e promoção do IAS. As categorias da análise de conteúdo com co-ocorrências que controlam o fluxo de informação (betweenness centrality) são indicadas de seguida por ordem decrescente. Importa ter em consideração que nem sempre os vértices que permitem maiores conectividades (betweenness centrality) coincidem com as categorias de maior frequência identificadas nas unidades de registro. 
- Promoção dos programas educacionais / atividades / resultados;

- Evidência científicas / pesquisas e estudos;

- Lembrança dos feitos de Ayrton Senna;

- Promoção de Seminários/eventos;

- Promoção das parecerias do Instituto.

Tabela 1 - Dados estatísticos dos vértices (categorias) da análise de rede a partir dos tweets do IAS 2013-2020

\begin{tabular}{|c|c|c|c|}
\hline & Degree & Betweenness Centrality & Closeness Centrality \\
\hline $\begin{array}{l}\text { Promoção dos programas educacionais / atividades / } \\
\text { resultados }\end{array}$ & 38 & 387,038 & 0,025 \\
\hline Evidências científicas/ pesquisas e estudos & 23 & 64,353 & 0,018 \\
\hline Promoção de Seminários/eventos & 20 & 39,456 & 0,017 \\
\hline Promoção das parecerias do Instituto & 15 & 21,687 & 0,016 \\
\hline Habilidades/ competências socioemocionais & 14 & 9,948 & 0,015 \\
\hline Angariação de fundos & 13 & 16,939 & 0,015 \\
\hline $\begin{array}{l}\text { Promoção de datas festivas (dia da mãe/ jovem / da leitura } \\
\text { / dia do ambiente) / prêmios }\end{array}$ & 13 & 12,183 & 0,015 \\
\hline Ensino médio & 12 & 10,161 & 0,015 \\
\hline Educação integral & 12 & 8,041 & 0,015 \\
\hline Atividades/ feitos da Presidente do Instituto Ayrton Senna & 11 & 9,223 & 0,015 \\
\hline Alfabetização & 11 & 3,016 & 0,015 \\
\hline Inovação em educação & 10 & 5,852 & 0,014 \\
\hline Criatividade/ pensamento crítico & 10 & 3,635 & 0,014 \\
\hline Lembrança dos feitos de Ayrton Senna & 9 & 40,975 & 0,014 \\
\hline $\begin{array}{l}\text { Conselhos/ atividades relacionadas com o período } \\
\text { pandemia/ pós-pandemia }\end{array}$ & 9 & 4,867 & 0,014 \\
\hline CTEM & 8 & 1,830 & 0,014 \\
\hline Base nacional curricular comum & 8 & 1,576 & 0,014 \\
\hline Instituto e as Org. Internacionais & 8 & 1,093 & 0,014 \\
\hline Citações & 7 & 2,394 & 0,014 \\
\hline Promoção da leitura/ escrita & 7 & 1,394 & 0,014 \\
\hline Habilidades/ competências para o sec. XXI & 6 & 0,500 & 0,014 \\
\hline Formação/ capacitação de professores & 6 & 0,492 & 0,014 \\
\hline Educação/ ensino de qualidade/ referência & 6 & 0,458 & 0,014 \\
\hline Rede/ Educação pública & 6 & 0,458 & 0,014 \\
\hline Esporte & 5 & 0,621 & 0,014 \\
\hline Direito à educação / Educação como um direito & 5 & 0,310 & 0,014 \\
\hline Promoção da revista/ tirinhas/ jogo Senninha & 4 & 0,500 & 0,014 \\
\hline Ensino fundamental & 4 & 0,000 & 0,013 \\
\hline Plano Nacional da Educação & 3 & 0,000 & 0,013 \\
\hline
\end{tabular}


Tabela 1 - Dados estatísticos dos vértices (categorias) da análise de rede a partir dos tweets do IAS 2013-2020

\begin{tabular}{|l|c|c|c|}
\hline & Degree & Betweenness Centrality & Closeness Centrality \\
\hline Habilidades/ competências para a Vida & 2 & 0,000 & 0,013 \\
\hline Ambiente e sustentabilidade & 2 & 0,000 & 0,013 \\
\hline Alimentação saudável & 2 & 0,000 & 0,013 \\
\hline $\begin{array}{l}\text { Mundo do trabalho/ empreendedorismo/ aprendizado mão } \\
\text { na massa }\end{array}$ & 2 & 0,000 & 0,013 \\
\hline Colaboração/ ligação com o governo & 2 & 0,000 & 0,013 \\
\hline Educação para todos & 2 & 0,000 & 0,013 \\
\hline Foco nos resultados da aprendizagem & 2 & 0,000 & 0,013 \\
\hline Economia/ finanças & 2 & 0,000 & 0,013 \\
\hline Meditação & 1 & 0,000 & 0,009 \\
\hline Ensino Superior & 1 & 0,000 & 0,013 \\
\hline Inglês & 1 & 0,000 & 0,013 \\
\hline
\end{tabular}

Fonte: elaborado pelos autores

\section{CONSIDERAÇÕES FINAIS}

O presente artigo, ao eleger como campo empírico a conta do Twitter do Instituto Ayrton Senna, buscou analisar como esta organização utilizou essa ferramenta no período de 2013 a 2020 para efeito de divulgar sua inserção na política educacional e calibrar sua incidência nesta área.. Para tanto, por meio de ferramenta de suporte para controle estatístico de frequência de palavras, o artigo buscou articular a análise de conteúdo à análise de rede para efeito de identificar as tendências expressas em suas publicações, os usuários mencionados, entendidos como interlocutores prioritários, e as agendas veiculadas.

Primeiramente, a análise global das categorias e a análise automática de frequência de palavras permitiu constatar que os principais objetivos da conta de Twitter do IAS são: ampliar a visibilidade dos programas e atividades que desenvolve, captar fundos para suas iniciativas e a promover seus parceiros. $\mathrm{Na}$ maioria das mensagens analisadas, estes objetivos associam-se a algum aspecto da política educacional.

Um segundo fator a destacar é que, em relação às categorias com mais unidades de registro relacionam-se à visibilidade e à promoção da "marca" Instituto Ayrton Senna. Muito provavelmente esta relevância relaciona-se ao fato de que a manutenção do IAS depende da angariação de fundos, ou seja, de doadores ou "parceiros", e da comercialização da marca e de produtos associados ao Ayrton Senna. Não obstante, estas categorias encontram-se associadas como 
se identificou no número elevado de co-ocorrências entre as unidades de registro. Destaca-se que, a categoria Promoção dos programas educacionais / atividades / resultados além de relacionar-se com a visibilidade do Instituto, parece associar-se com estratégias de legitimação do IAS no campo da educação.

Um terceiro aspecto a destacar, refere-se à importância dada nos tweets às questões inerentes à ciência, tecnologia, engenharia e matemática (CTEM) e à defesa das habilidades/competências socioemocionais, temas que integram a agenda da OCDE, organização, não por caso, que se percebe como um dos principais atores acionados pelo IAS nesta rede social.

Já a relevância dada ao uso de evidências científicas, pesquisas, citações ou estudos associa-se à disseminação de programas ou temas defendidos pelo Instituto em âmbito nacional e se apresenta como estratégia para difundir com aparente neutralidade uma determinada posição. Recorrendo ao que pode ser denominado por "evidências", o IAS parece tentar imputar a terceiros suas opções educacionais. Assim, ao evocar estudos científicos específicos ou "pinçados" e disseminar experiências educativas chanceladas como "boas práticas", parece dissimular suas opções políticas transferindo-as para atores externos.

Há que se ressaltar que a produção científica exige o debate ético e transparente com o contraditório. Frisa-se que, em qualquer situação, as evidências e boas práticas disseminadas como definitivas podem ter por base resultados contestados por outras pesquisas, serem parciais e/ ou apresentarem um enquadramento ideológico. Nesses termos, o IAS incorpora algumas características pós-políticas já observadas em outras organizações por estudos como KNUTSSON e LINDBERG (2020).

É nessa direção que se apresentam as menções à OCDE e à UNESCO. Importante indicar que a chancela que o IAS recebeu da UNESCO e a parceria com a OCDE são mencionadas para referendar ações e opções associadas à adoção de competência ou habilidades socioemocionais nos currículos escolares. Sobre esta categoria, importa informar que o IAS organizou em 2014, com o apoio do MEC e da OCDE, evento para discussão preliminar do documento "Estudos da OCDE sobre competências Competências para o progresso social. O poder das competências socioemocionais". (VINCENT-LANCRIN, 2015). Em âmbito nacional, os usuários mais frequentemente mencionados no período foram o PORVIR e a Fundação Lemann, atores privados diretamente vinculados a reformas educacionais em diferentes estados e municípios, com ênfase em propostas para o uso de tecnologias educacionais. 
A análise por ano civil mostra que entre 2013 e 2014 emergem duas categorias que não voltam a ganhar relevância nos anos seguintes - Educação/ ensino de qualidade/ referência e Rede/ Educação pública - e nos anos de 2015 a 2019 predominam as categorias Evidência científicas/ pesquisas e estudos, CTEM e Citacões.

A centralidade que a categoria CTEM assume nos tweets entre 2015 e 2019 pode estar associada à implementação pelo IAS, entre maio de 2016 e dezembro de 2017 na cidade catarinense de Chapecó, com o apoio da Secretaria de Educação do Estado de Santa Catarina, da Secretaria de Educação de Chapecó e da Federação das Indústrias do Estado de Santa Catarina (Fiesc), do projeto "Desenvolvimento e Avaliação da Criatividade e do Pensamento Crítico na Educação", proposto pelo Centro de Pesquisa e Inovação em Educação da OCDE (OCDE-CERI). De modo que os tweets amplificariam a relevância do tema tendo em vista uma ação do IAS.

Já no ano de 2020, devido à pandemia de COVID19, assistimos à emersão da categoria Conselhos/ atividades relacionadas com o período pandemial pós-pandemia e uma maior preponderância da categoria Competências socioemocionais.

Em síntese, o estudo, adotando metodologia pouco acionada pela pesquisa em educação no Brasil, a partir da análise de um caso específico, ilustra o movimento de autolegitimação adotado pelos agentes políticos nas redes sociais para amplificar sua inserção no campo em que atuam. Para a pesquisa em educação, especialmente para aqueles que analisam a atuação de agentes/atores ou sujeitos na disputa pelas prioridades em política educacional faz-se mister incorporar aos estudos, esse espaço virtual, em que a visibilidade é fundamental e os \# substituem os encontros.

\section{REFERENNCIAS}

ADRIÃO, T e PERONI, V. Consequências da atuação do Instituto Ayrton Senna para a gestão da educação pública: observações sobre 10 estudos de casos. Práxis Educativa, v 6 (1), p. 45-53. 2011.

ADRIÃO, T. Dimensões e Formas da Privatização da Educação no Brasil: caracterização a partir de mapeamento de produções nacionais e internacionais. Currículo sem fronteiras, v. 18, p. 8-28, 2018.

ADRIÃO, T.; DOMICIANO, C. A. A Educação Pública e as Corporações: avanços e contradições numa década de ampliação de investimento no Brasil. FINEDUCA - Revista de Financiamento da Educação, Porto Alegre, v. 8, n. 3, p. 1-18, 2018. DOI: https:/ / doi.org/10.17648/ fineduca2236-5907-v8-79084 
BARDIN, L. Análise de conteúdo. 4. ${ }^{a}$ ed. Lisboa: Edições 70, 2007.

BISHOP, M.; GREEN, M. Philanthrocapitalism Rising. Society, 52, n. 6, p. 541-548, 2015.

BLOMMAERT, J. Political Discourse in Post-Digital Societies. Trabalhos em Linguística Aplicada, 59, p. 390-403, 2020.

FREITAS, Luiz CARLOS de. Os reformadores empresariais da educação: da desmoralização do magistério à destruição do sistema público de educação. Educ. Soc., Jun 2012, vol.33, no.119, p.379-404.

GENTIL, D., FERREIRA, G. T. C. Como as Empresas Integrantes da Carteira ISE Avaliam o Retorno do Investimento Social Privado. Organizações em contexto v. 15 (29), p. 97-123. 2019.

HANSEN, D. L.; SHNEIDERMAN, B.; SMITH, M. A.; HIMELBOIM, I. Analyzing social media networks with NodeXL: Insights from a Connected World. Cambridge: Elsevier, 2020.

KNUTSSON, B.; LINDBERG, J. Depoliticisation and dissensus in the global partnership for education: rethinking the post-political condition. Journal of International Relations and Development, 23, n. 2, p. 436-461, 2020.

MARTELETO, R. M. Análise de redes sociais - aplicação nos estudos de transferência da informação. Ciência da Informação, 30, p. 71-81, 2001

MARTINS, E. Todos pela educação? Como os empresários estão determinando a política educacional brasileira. Lamparina; 1ª edição, 2016.

MELLO, J., PEREIRA, A. C. R. E ANDRADE, P. G. Afinal, o que os dados mostram sobre a atuação das ONGs? Análise de transferências federais e projetos executados pelas organizações da sociedade civil no Brasil. Texto para discussão 2483 do Instituto de Pesquisa Econômica Aplicada. Brasília: IPEA. 2019.

OLIVEIRA, E. et al. Análise de conteúdo e pesquisa na área da educação. Revista Diálogo Educacional, [S.1.], v. 4, n. 9, p. 11-27, jul. 2003. 
SAM, C. H. Shaping Discourse Through Social Media: Using Foucauldian Discourse Analysis to Explore the Narratives That Influence Educational Policy. American Behavioral Scientist, 63, n. 3, p. 333-350, 2019.

SCHUSTER, J.; JÖRGENS, H.; KOLLECK, N. The rise of global policy networks in education: analyzing Twitter debates on inclusive education using social network analysis. Journal of Education Policy, p. 1-21, 2019.

THELWALL, M.; CUGELMAN, B. Monitoring Twitter Strategies to Discover Resonating Topics: the case of the UNDP. El profesional de la información, 26, n. 4, p. 649-661, 2017.

VINCENT-LANCRIN, S. et al. Competências para o progresso social: o poder das competências socioemocionais. São Paulo: Fundação Santillana, 2015.

WELLER, K.; BRUNS, A.; BURGESS, J.; MAHRT, M. et al. Twitter and society. Nova Yorque: Peter Lang, 2014.

\section{Rui Manuel Ferreira da Silva}

Possui doutorado e mestrado em Ciências da Educação, especialidade de Desenvolvimento Curricular na Universidade do Minho. É Investigador integrado do Centro de Estudos Africanos da Universidade do Porto a desenvolver atualmente o projeto de investigação financiado pela Fundação para a Ciência e Tecnologia "Comparative study on the compulsory education privatization in small states: examining the role and impact in Cape Verde and Guinea-Bissau." Desenvolve pesquisas na área de política educacional, com ênfase nas relações entre o público e o privado no campo educacional no Sul Global, avaliação de efeitos e impactos de projetos de cooperação para o desenvolvimento; e políticas educativas globais e o direito à educação. Desenvolveu trabalho como investigador, consultor e especialista de educação em projetos/ programas de cooperação para o desenvolvimento em Angola, Cabo Verde, Guiné-Bissau, Sudão do Sul e Timor-Leste. Tem experiência em consultoria na área da educação em cooperação para o desenvolvimento, tendo já realizado trabalho de avaliação, monitorização e diagnóstico. E-mail: rdasilva.email@gmail.com 


\section{Theresa Maria de Freitas Adrião}

Possui graduação em Pedagogia pela Universidade de São Paulo (1988), mestrado em Educação pela Universidade de São Paulo (1995) e doutorado em Educação pela Universidade de São Paulo (2001) e Livre Docente pela UNICAMP. É professora colaboradora e pesquisadora do Programa de Pós Graduação da UNICAMP e Professora Visitante na UNEMAT. Desenvolve pesquisas na área de política educacional, com ênfase em gestão e financiamento da educação básica, incluindo estudos sobre privatização. Publicou diversos livros e artigos sobre os temas de investigação. Coordena o Grupo de Estudos e Pesquisas em Políticas Educacionais (GREPPE/UNICAMP) e a Rede de Latino Americana e Africana de Pesquisadores em Privatização da Educação. (RELAAPE/https://www.rede. fe.unicamp.br/pt-br ). Integra as seguintes entidades acadêmicas e cientificas: ANPED (Tendo sido coordenadora do GT Estado e Política Educacional de 2015 a 2019); Vice diretora Estadual/SP da ANPAE (2015-2017); FINEDUCA e CEDES. Editora da Revista Educação e Sociedade (2018-2020) Bolsista PQ/ CNPq - 2010 a 2017 e 2020 a 2023. E-mail: theadriao@gmail.com

Recebido em: 16/02/2021

Aprovado em: 16/04/2021 